\title{
Avaliando a temática inclusão no contexto da revista Nova Escola: corpo, produção de conhecimento e imaginário social em discussão
}

\author{
Samuel Gonçalves Pinto
}

Carlos da Fonseca Brandão

Chelsea M. de Campos Martins

\section{Resumo}

A presente pesquisa buscou investigar as edições e reportagens da Revista Nova Escola durante o período de 2003-2010, utilizando-se como critério, as que abordaram o tema inclusão enquanto política pública. O procedimento metodológico aplicado por meio da análise do discurso de sete textos avaliados, sendo seis reportagens e uma entrevista. A revista por se direcionar ao docente enquanto potencial leitor, trata de temas pertinentes à sua atuação profissional, se mostrando assim, um potencial instrumento formativo. Pode-se concluir que o tema da inclusão foi debatido e defendido como ação positiva, desde a inclusão de pessoas com deficiência, passando pela inclusão de gênero à inclusão digital. Contudo, no contexto de analisar a temática inclusão diante à postura das reportagens publicadas na Revista Nova Escola, constatou-se que apenas uma reportagem tratou da questão inclusão enquanto política pública, no entanto, se posicionando de forma positiva e sem crítica dessa questão, limitando-se aos aspectos de âmbito escolar.

Palavras-chave: Inclusão; Revista Nova Escola; Avaliação 


\title{
Large scale and curriculum evaluation: relations between PISA and BNCC
}

\author{
Samuel Gonçalves Pinto
}

Carlos da Fonseca Brandão

Chelsea M. de Campos Martins

\section{Abstract}

The present research sought to investigate the editions and reports of Revista Nova Escola during the 2003-2010 period, using as a criterion those that approached the theme inclusion as public policy. The methodological procedure applied through the discourse analysis of seven texts evaluated, with six reports and one interview. The mentioned magazine, because it is directed to the teacher as a potential reader, deals with themes pertinent to their professional performance, and thus shows a potential formative instrument. It can be concluded that the theme of inclusion was debated and defended as a positive action, from the inclusion of people with disabilities, to the inclusion of gender in digital inclusion. However, in the context of analyzing the inclusion theme in view of the stance of the articles published in Revista Nova Escola, it was verified that only one article dealt with the inclusion issue as a public policy, however, positively and uncritically positioning this issue, limiting school aspects.

Keywords: Inclusion; Revista Nova Escola; Evaluation 


\section{Introdução}

A presente pesquisa buscou analisar todas as edições e reportagens da Revista Nova Escola durante o período de 2003-2010, utilizando-se como critério, as que abordaram o tema inclusão enquanto política pública verificaram-se sete reportagens: "Inclusão que funciona" cujo autor Arthur Guimarães (Capa - Edição n. 165, Setembro de 2003); "Sala de aula sem preconceito" autora Cláudia C. Moro (Com a palavra -, Abril de 2004); “Aparências diferentes? Talentos também”, autora Meire Cavalcante (Edição n. 173, Junho/Julho de 2004); "A sociedade em busca de mais tolerância”, autora Meire Cavalcante (Edição n. 196, Outubro de 2006); "Falta cultura digital na sala de aula" autora Débora Didonê (Edição n. 200, Março de 2007); “Juntos, todos aprendem mais” Denise Pellegrini (Edição n. 201, Abril de 2007); "Inclusão, só com aprendizagem", autora Thais Gurgel, com a colaboração de Débora Didonê e Paulo Araujo (Edição 206, Outubro de 2007).

Neste sentido, a organização do artigo está estruturada em duas partes, sendo que a primeira parte aborda a questão do imaginário social e a produção de conhecimento por estabelecer as relações de interdependências no contexto social, bem como influenciando a formação dos professores e a segunda parte, analisamos o tema proposto na perspectiva da Revista Nova Escola, por ser essa revista considerada de abrangência nacional no meio educacional em que várias redes de ensino estaduais e ou municipais utilizam enquanto recurso pedagógico de formação docente.

\section{Corpo, Imaginário Social e a questão da Produção de Conhecimento: olhares preliminares}

As relações estabelecidas pelos indivíduos em suas trajetórias fazem com que os mesmos carreguem consigo conceitos, perspectivas, sentidos e ideais representados através de símbolos. As significações e relações de interdependências simbólicas se estabelecem em cada ordem social, sendo constantemente influenciadas pela questão do imaginário.

Assim, o corpo se apresenta como receptáculo, expondo construções simbólicas frente a estímulos recebidos, com a realidade na qual estejamos envolvidos, em que valores são expressos num processo constituído histórico-cultural. Sujeitos a interesses, necessidades, manipulações e fragmentações.

A possibilidade de produção de conhecimento articula-se com aprendizado, com mudanças. As subjetividades que envolvem esse contexto com a questão do corpo podem ser reveladas a partir de nuances existentes no Imaginário Social ${ }^{18}$. Vida humana, produções

\footnotetext{
${ }^{18}$ Para Bronislaw Baczko, o imaginário social é composto por um conjunto de relações imagéticas que atuam como memória afetivo-social de uma cultura, um substrato ideológico mantido pela comunidade. Trata-se de uma produção coletiva, já que é o depositário da memória que a família e os grupos recolhem de seus contatos com o cotidiano. Nessa dimensão, identificamos as diferentes percepções dos atores em relação a si mesmos e de uns em ISSN 2526-2882
} 
imaginárias e conhecimento, apresentam contornos e perspectivas para a o cotidiano. Dessa forma faz se necessário pensar essa relação dentro de um contexto que considere e dê relevância a questão da identidade, o que pensam, o que querem e a construção imaginária existente.

A partir do seu potencial de expressividade e dos seus múltiplos significados, o corpo, ao longo da história, passa a se comunicar com o mundo por meio das relações estabelecidas em diferentes contextos sociais. Em virtude desses significados e signos, o corpo passa a se expressar interagindo com o mundo que o cerca, expressando-se de maneiras diferenciadas de acordo com os estímulos intrínsecos ou extrínsecos recebidos em seu cotidiano.

Esses trechos e caminhos do corpo o apresentam como construção cultural. Geertz (1989), aponta que é por meio desse mecanismo chamado cultura que o homem adquiriu a capacidade de ser o construtor de sua própria história, desde a utilização de ferramentas, passando pelo convívio social, pela linguagem chegando a outras formas mais complexas de significar o fazer humano. O autor demonstra, com isto, como o convívio entre povos foi tecendo uma teia de significados que foram ganhando densidade ao longo da história da humanidade, significados estes que, por sua vez, estão em constante processo de ressignificação.

O conceito de cultura proposto por Geertz (1989, p.15) tem forte influência das ideias de Max Weber, uma vez que para este “...o homem é um animal amarrado a teias de significados que ele mesmo teceu”. Geertz (1989) ao balizar-se neste conceito, afirma que para entender o que é cultura, e como ela influencia as ações de um determinado grupo, é preciso identificar e perceber como as pessoas são, como se relacionam, como agem e interagem, é, portanto, ir além do visível, é mergulhar, de fato, no significado das ações desenvolvidas pelos indivíduos em suas sociedades.

O corpo é um agente de cultura que traz impressas as marcas de um povo. Constitui uma superfície na qual as normas culturais são inscritas e reforçadas pela linguagem corporal (BORDO, 1997). Por meio de diversos processos de inculcação, a sociedade imprime nos sujeitos e em seus corpos não apenas um modo de ser e estar, mas todo "um programa de percepção" que determina aos indivíduos a maneira de perceber seus próprios corpos (BOURDIEU, 1995).

Tratando ainda dessa relação entre corpo e cultura, percebemos em Certeau (1982), que “...cada sociedade tem seu corpo, assim como ela tem sua língua”. Pensar o corpo dessa

relação aos outros, ou seja, como eles se visualizam como partes de uma coletividade. Bronislaw Baczko assinala que é por meio do imaginário que se podem atingir as aspirações, os medos e as esperanças de um povo. É nele que as sociedades esboçam suas identidades e objetivos, detectam seus inimigos e, ainda, organizam seu passado, presente e futuro. O imaginário social expressa-se por ideologias e utopias, e também por símbolos, alegorias, rituais e mitos. Tais elementos plasmam visões de mundo e modelam condutas e estilos de vida, em movimentos contínuos ou descontínuos de preservação da ordem vigente ou de introdução de mudanças. 
forma implica considerá-lo como passível de mudanças, funcionando como uma memória mutante das leis e dos códigos de cada cultura, demonstrando os limites científicos e tecnológicos de cada época e as soluções elaborados por diferentes sociedades, por construções imaginárias.

Bachelard (1988) em “A Poética do Devaneio" nos apresenta que a imaginação tenta um futuro. A princípio ela é um fator de imprudência que nos afasta das pesadas estabilidades, certos devaneios poéticos são hipóteses de vidas que alargam a nossa vida dando-nos confiança no universo. Um mundo se forma no nosso devaneio, um mundo que é o nosso mundo. E esse mundo sonhado ensina-nos possibilidades de engrandecimento de nosso ser nesse universo que é o nosso.

O conhecimento está presente no nosso cotidiano em diversas áreas, as quais têm maneiras diferentes de entendimentos, delineando proposições, ao revelar ideais e perspectivas que traçam um "modo" de pensar, ou seja, oferecem sua lente para a leitura da realidade. $\mathrm{O}$ ato de conhecer implica pessoas, num dado momento, nas esferas de suas vidas, em diferentes aspectos e a expressão/absorção desse conhecimento se desvela de várias formas, através da escrita, da oralidade, dos gestos, em que palavras, sons e imagens interagem na construção de significados.

A relação entre conhecimento, pertencimento e aplicabilidade ao cotidiano se apresentam como condicionantes para as articulações entre saber e fazer. Os conceitos de "mudanças ou transformação" que se articulam com o processo de formação "possuem conotação valorativa: mudar ou transformar uma prática pedagógica significa fazê-la avançar em direção a intencionalidade e valores explicitados e assumidos” (ROSSI, 2013, p. 13). Assim, participar desse processo significa se envolver com a possibilidade de (re)leituras, envolvem o traçar de ressignificações.

Imbernón (2009) nos apresenta que as novas tendências da formação continuada de professores pressupõem uma tarefa coletiva, ou seja, o desenvolvimento de atividades de formação colaborativa entre instituições formadas e escolas, estabelecendo relações de parcerias e cooperação entre sujeitos envolvidos. O trabalho conjunto dos diferentes atores sociais tem intuito de solucionar as situações problemáticas das práticas educativas, ao viabilizar processos próprios de intervenção, correspondendo de forma mais adequada ao momento histórico vivido por determinado sujeito/grupo.

Conforme Hunger et al. (2013) o que se verifica na atualidade é a formação de grupos que se tornam cada vez mais funcionalmente dependentes uns dos outros, com funções especializadas e específicas no campo educacional (professores, diretores, coordenadores, supervisores, agentes formadores, pesquisadores, governantes, alunos, pais, comunidade). Assim, as cadeias de interdependência tornam-se mais diferenciadas, consequentemente mais 
opacas e mais incontroláveis por parte de um grupo ou individuo (ELIAS, 1980). E tais grupos exercem influência mútua, tem poder uns sobre os outros, considerando que o poder, na ótica do autor, é flutuante, elástico e não se trata de algo que apenas um grupo possui e outro não. Contudo, existe um equilíbrio desse poder, podendo em determinado momento histórico, essa balança pender mais para um lado eu para outro.

Essa relação com estruturas de poder se apresenta face à detenção dos mecanismos que controlam a atividade produtiva, a relação estabelecida entre acreditar no impacto de suas ações, a relevância e qualidade das mesmas pode apresentar diferentes polarizações. Forças e energias se relacionam com controle, eficiência e produtividade, o corpo assim se apresenta como uma superfície de inscrição dos conteúdos simbólicos que perpassam a estrutura social e um lugar diretivo de controle desta estrutura.

Observa-se, ao olhar para a formação continuada na perspectiva de Elias (1980), que nesse contexto a distribuição de poder entre os grupos apresenta-se desigual, ocupando o professor o lugar de sujeito passivo na sua própria formação, receptor de conteúdos elaborados por outros. E, nesse sentido, as ações formativas estão configuradas não como processos compartilhados entre esses diferentes grupos, mas como processos elaborados unilateralmente. Nesse jogo de forças, a capacidade de controle irá variar de acordo com as posições ocupadas pelas pessoas nesse momento histórico, a dependência mútua existente entre os grupos e as tensões e conflitos inerentes à teia entrelaçada (ROSSI, 2010, 2013).

\section{Conhecimento e Imaginário Social: em busca de explicações sobre teorias, conceitos e perspectivas}

A ciência tece junto campos antes considerados distintos, como a totalidade estruturada e racionalizada do mundo econômico e político e as estruturas cotidianas constitutivas das experiências emocionais e psicológicas, como nos ensina Morin (2000, p. 38):

O conhecimento pertinente deve enfrentar a complexidade. Complexus significa o que foi tecido junto; de fato, há complexidade quando elementos diferentes são inseparáveis constitutivos do todo (como o econômico, o político, o sociológico, o psicológico, o afetivo, o mitológico), e há um tecido interdependente, interativo e inter-retroativo entre o objeto de conhecimento e seu contexto, as partes e o todo, o todo e as partes, as partes entre si.

O estudo sobre o imaginário social possibilita um novo olhar sobre os sentidos que o conhecimento vem assumindo em nossa sociedade, por permitir que os atores sociais apresentem construções perceptivas presentes no imaginário, as correlações existentes entre as estruturas sociais e as representações que esta prática possui na vida social. "Investigá-lo significa adentrar pelas vias das linguagens, admití-lo como algo que se institui/instituindo sentido à vida humana" (FERREIRA; EIZIRIK, 1994, p.5). As autoras afirmam que o ISSN 2526-2882 
"imaginário social reflete práticas sociais em que se dialetizam processos de entendimento e de fabulação de crenças e de ritualizações”. A análise destas crenças e o seu entendimento, contribuirá para as reflexões sobre os sentidos e significados que circulam na sociedade, sobre determinado conhecimento. Mas principalmente a compreensão das relações hierárquicas da sociedade, através dos rituais que fazem crer que são naturais. (FERREIRA; EIZIRIK, 1994, p.7)

Assim, para compreensão do "imaginário social”, nesta pesquisa, serão utilizados como referenciais teóricos estudos que discutem o tema, a partir da perspectiva que CASTORIADIS (1982) apresenta em "A instituição imaginária da sociedade". A escolha deste autor, como embasamento teórico, deve-se pela riquíssima abordagem em suas obras sobre a constituição da sociedade e a necessidade de autonomia política.

A fim de compreender a instituição imaginária (sociedade), Castoriadis (1982), em “A instituição imaginária da sociedade", afirma que a sociedade seria produto de uma instituição imaginária, e, a partir deste pressuposto, propõe uma nova visão teórica do social, baseada no social-/histórico e o imaginário, as significações e as representações deste. Conceitua imaginário como a:

"criação incessante e essencialmente indeterminada (social-histórica e psíquica) de figuras/formas/imagens, partir das quais somente pode ser questão de 'qualquer coisa'. O que nós chamamos 'realidade' e 'racionalidade' são suas obras" (CASTORÍADIS, 1982, p. 41).

O imaginário, segundo o autor, seria o despertar de um "sono dogmático", petrificado pela realidade histórico-social e de uma dimensão de criação continuada. E este despertar gera desconfianças, incertezas, dúvidas das verdades instituídas socialmente. Estas inquietações advêm da descoberta de que "o real e o ideal, o concreto e o abstrato, a matéria e as relações são conceitos instituídos socialmente e que neles está presente o modo de produção de seus sentidos" (FERREIRA; EIZIRIK, 1994).

Segundo Castoriadis (1982), quando falamos de imaginário, referimo-nos a uma invenção absoluta, uma história imaginada em todas as suas partes; além de inferir que o imaginário se separa do real devido ao deslocamento de sentido dos símbolos, já disponíveis, quando são colocados em lugares de "mentira". Diante deste dualismo entre real e imaginado, o imaginário gera produtos que são a realidade e a racionalidade.

Para entender esta lógica, identitária ou conjuntivista, da sociedade sobre o socialhistórico e o imaginário, as significações, a representação, Castoriadis (1982) se debruça sobre as significações imaginárias sociais, os símbolos, e as relações de poder nas instituições. Segundo ele, o imaginário social é criado a partir das significações imaginárias sociais e da instituição; “...da instituição como presentificação destas significações e destas significações ISSN 2526-2882 
como instituídas”. Pois, o mundo social-histórico está indissociavelmente entrelaçado com o simbólico, as instituições estão cheias de elementos simbólicos e o simbolismo está cheio de imaginário.

O autor mostra que há uma indissociabilidade entre o mundo social-histórico e os símbolos, pois as ações, os atos reais, individuais ou coletivos, não existem sem uma rede simbólica. Esta rede simbólica se manifesta na linguagem e em outros símbolos presentes nas instituições. As instituições existem no símbolo, constituindo uma rede de símbolos. Os sistemas simbólicos são responsáveis pela ligação dos símbolos, e a constituição das redes, segundo Castoriadis (1982).

Neste processo de ligação dos símbolos, ocorrem as operações simbólicas que expressam conteúdos preexistentes de relações sociais, os simbolismos não são neutros, pois são implicações ou consequências lógico-racionais das considerações precedentes as estes símbolos:

...nada permite determinar a priori o lugar por onde passará a fronteira do simbólico, o ponto a partir do qual o simbólico invade o funcional. Não podemos fixar nem o grau geral de simbolização, variável segundo as culturas, nem os fatores que fazem com que a simbolização se exerça com uma intensidade particular sobre tal aspecto da vida da sociedade considerada (CASTORIADIS, 1982, p. 144).

A constituição dos símbolos na sociedade é diretamente dependente do natural e do histórico das instituições, o que permite o surgimento de encadeamento de significantes relações não previstas. Mas o fato principal, deste processo é o papel que o simbolismo tem na determinação dos aspectos da vida da sociedade.

Assim, o Imaginário Social é uma rede de sentidos que são entrelaçados pelas atividades da razão e da imaginação, através de um processo de simbolização. Esta rede tem por objetivo fazer a ligação de "símbolos (significantes) a significados (representações, ordens, injunções ou incitações par a fazer ou não fazer, consequências e significações, no sentido amplo do termo) e fazê-los valer como tais, ou seja, a tornar esta ligação mais ou menos forçosa para a sociedade ou o grupo considerado" (CASTORIADIS, 1982, p. 142).

Em face, a estas relações simbólicas em cada cultura, corroborando com Ferreira e Eizirik (1994, p.6), observa-se que "as informações que circulam na sociedade têm relações diretas com o Imaginário Social. Isto quer dizer, com os meios pelos quais se difunde esse imaginário". Para compreensão das significações imaginárias sociais, o autor, afirma que é preciso compreender como uma sociedade faz seu simbolismo, a nível de imaginário; compreender e captar as significações dadas aos símbolos, por meio das estruturas significantes; e compreender esse processo de automização dos símbolos na vida social. Mas neste processo, de compreensão das significações simbólicas, é preciso ter claro que as ISSN 2526-2882 
significações podem corresponder ao percebido, ao racional ou ao imaginário.

Defronte a estas colocações, pondera-se sobre a importância de se compreender a história humana, que está relacionada a categoria imaginário; pois não é possível compreendêla sem um conteúdo significado e o entrelace com as estruturas simbólicas. Segundo Castoriadis (1982), o simbólico-racional é definido como aquilo que representa o real ou então é indispensável para pensá-lo ou para agi-lo.

Para compreensão das significações imaginárias sociais, é preciso compreender a relação existente com a realidade. Segundo Castoriadis (1982), esta realidade natural, tem que estar suscetível a transformações, e se deixar alterar “condicionalmente”, diante de interstícios livres e regrados. A realidade natural é essencial para o fazer social no que tange ao mover e mover-se, transportar e deslocar-se, cortar, juntar no processo de construção do mundo das significações.

Castoriadis (1982, p. 404) afirma que a sociedade faz ser um mundo de significações, pois a instituição da sociedade é instituição do fazer social e do representar/dizer social:

\begin{abstract}
A instituição da sociedade é toda vez instituição de um magma de significações imaginárias sociais, que podemos e devemos denominar um mundo de significações. Porque é o mesmo dizer que a sociedade institui cada vez o mundo como seu mundo ou seu mundo como o mundo, e dizer que ela institui um mundo de significações, que ele se institui instituindo o mundo de significações que é o seu e correlativamente ao qual somente um mundo existe e pode existir para ela.
\end{abstract}

Esse fazer social se relaciona a deslocamentos de sentido atribuídos a vivências, sentimentos, reações frente às observações, pensamentos e imaginações. O mover-se, transportar e deslocar-se, assim ganha voo no processo de construção do mundo das significações.

\title{
Análise dos textos
}

Com o intuito de verificar o posicionamento da Revista Nova Escola referente à inclusão apresentaremos análise individualmente das reportagens mencionadas. Utilizandose da ordem cronológica, em setembro de 2003, a Revista teve enquanto capa a temática inclusão, cujo título "Inclusão que funciona", de autoria de Arthur Guimarães, tratou da inclusão de forma bastante complexa.

Nesse contexto, a reportagem, dentre os diversos aspectos, discorreu principalmente sobre a importância da inclusão, dos cuidados diferentes para cada deficiência, das ações integradas da inclusão e sugestões de contatos e informações referentes às instituições afins.

Na perspectiva de verificar o posicionamento da reportagem referida, percebe-se que a apreensão dada à temática inclusão, transcendeu a questão de atendimento aos dispositivos 
legais, na medida em que diversas ações foram demonstradas mais importantes como oferecer uma proposta pedagógica que ofereça um currículo adaptado à necessidade dos alunos de inclusão significa: "oferecer serviços complementares, adotar práticas criativas na sala de aula, adaptar o projeto pedagógico, rever posturas e construir uma nova filosofia educativa" (GUIMARÂES, 2003, p.43).

Assim, observa-se a postura favorável sobre a discussão do tema da inclusão e da matrícula de crianças com deficiência na rede regular de ensino com uma proposta pedagógica inclusiva, pois para Guimarães "nunca o tema da inclusão de crianças com deficiência ser tão presente no dia-a-dia da educação - isso é uma ótima notícia” (GUIMARÂES, 2003, p.44).

Além disso, a reportagem segue com subtítulos, como "Mudar é difícil, mas compensa" o qual se observou semanticamente percebemos o contraste na afirmativa favorável à inclusão. Nesse mesmo corpo de texto trouxe as perspectivas pedagógicas dando a palavra a Maria Teresa Mantoan, coordenadora do Laboratório de Estudos e Pesquisas em Ensino e Diversidade da Universidade de Campinas, que afirma “[...] a construção desse modelo implica transformar a escola, no que diz respeito ao currículo, à avaliação e, principalmente, às atitudes. [...] Não podemos continuar segregando essas crianças em escolas especiais, que oferecem um ensino pouco estimulante" (GUIMARÂES, p.44, 2003).

Entretanto, na dimensão de gestão (burocrático), o autor utilizou-se das palavras de Claudia Dutra, Secretária de Educação Especial do Ministério da Educação, indagando a incumbência do "corpo diretivo buscar orientação e suporte das associações de assistência e das autoridades médicas e educacionais sempre que a matrícula de um deficiente é solicitada" (GUIMARÂES, p.44, 2003).

Com relação ao percentual de alunos com deficiência que estudavam em escolares regulares, informou, com base no Censo de 2002, a grande crescimento desses percentuais o autor afirma: “[...] desde 1998, aumentou 135\% - mas ainda é minoria. Cerca de 340 mil crianças com deficiência [...] estão segregadas" (GUIMARÂES, p.44, 2003).

Guimarães (2003) ao finalizar o texto direciona para a questão do currículo adaptado, contudo distante de um posicionamento frente à temática inclusão enquanto política pública, nos subtítulos seguintes "Todos juntos, sem preconceito" e "Agora, as aulas fazem sentido" a reportagem, utilizando-se de exemplo de gestão, a questão da inclusão na rede município de ensino de Sorocaba/SP e suas principais medidas relacionadas à elaboração de proposta pedagógica e de diagnóstico de demanda; criação de currículo que reflita o meio social; apoio à descentralização da gestão administrativa; oferta de transporte escolar para todos. Na sequência, a mesma trouxe depoimentos de uma professora do ensino público e uma coordenadora e diretora de Associações dos Familiares e Amigos do Down os quais diziam terem reavaliados suas posturas pedagógicas no intuito de melhorá-las. 
Na reportagem "Sala de aula sem preconceito" a autora Cláudia C. Moro, tratou de analisar a questão da inclusão, considerando a dimensão de gênero no contexto da prática docente na área de Ciências ao indagar: "A discriminação nas ciências naturais exatas é apenas uma das facetas do preconceito contra o sexo feminino" (MORO p.21, 2004).

Tal reportagem aponta que diversos são os estudos que mostram a existência da discriminação desde a sala de aula enquanto um dos fatores do menor interesse de mulheres no mundo científico, sem a pretensão de analisar esta questão enquanto política pública.

Na reportagem "Aparências diferentes? Talentos também”, de Meire Cavalcante, o foco de suas análises - bem como direcionado no título e na escolha do adjetivo "diferentes" e dos substantivos "Aparências" e "Talentos" que o contraste pode ser positivo, quando o talento passa a ser valorizado e não anulado ante as aparências - se pautou na dimensão da postura e incentivos no desenvolvimento das habilidades dos estudantes de inclusão. No entanto, indagou que "a sociedade brasileira ainda engatinha no que se refere à inclusão" (CAVALCANTE, p.32, 2004), reflexo da falta de informação e do preconceito, sem a pretensão de analisar a temática enquanto política pública.

A reportagem “A sociedade em busca de mais tolerância”, de autoria Meire Cavalcante, tratou da temática inclusão no contexto da contribuição em que a escola no combate à discriminação e de possibilitar a aprendizagem dos portadores de deficiência.

Vale ressaltar que a reportagem mencionada, indagou que a intolerância tem relação intrínseca com o comportamento aprendido historicamente e que, a resistência inicia-se na própria família e que a escola (nas atitudes do educador) apresenta-se na possibilidade de significar espaço de mudança de paradigma.

Dessa maneira, segundo a jornalista "mesmo depois da de 18 anos da promulgação da Constituição, que prevê 'igualdade de condições para o acesso e permanência na escola" a intolerância ainda se faz presente entre os educadores, pais, alunos e funcionários, a qual deve combatida, dentre outras maneiras, pela difusão da informação e conhecimento sobre o assunto. A reportagem é finalizada com um quadro com nove indicações sobre "Atitudes do educador que incluí", destacamos a primeira em que diz que o educador que inclui: "Procura conhecer a legislação que garante o direito à Educação das pessoas com deficiência" (CAVALCANTE, p.36, 2004).

Na reportagem “Juntos, todos aprendemos mais", de autoria de Denise Pellegrini, mostrou as ações da EMEF Armando Cavazza, de Barueri/SP desenvolveu no sentido de incluir os alunos com deficiência no ensino regular, adaptando seu projeto pedagógico à legislação vigente (a ideia, uma das vencedoras do Prêmio Víctor Civita Educador Nota 10, em 2006). Dentre as diversas ações, foram desenvolvidas "atividades por etapa, planejando situações de sensibilização do grupo ao longo do tempo", por meio de recreio coletivo, oficinas de arte, 
interação aluno e alunos portadores, rodízio de tutores, formação específicas aos docentes, sala de recursos - “como previsto pela lei”. Porém não desenvolve a discussão a partir da perspectiva enquanto política pública.

A entrevista "Falta cultura digital na sala de aula", de Débora Didonê com o entrevistado filósofo e professor Pier Cesare Rivoltella, especialista em Mídia e Educação da Universidade Católica de Milão, na Itália, além de “orientar pesquisas sobre a relação entre jovens e internet no Grupo de Pesquisa Educação e Mídia da Pontifícia Universidade Católica do Rio de Janeiro (PUC/RJ), onde também dá aulas sobre Mídia e Educação, e acompanha pesquisas de mestrado na Universidade Federal de Santa Catarina”, trouxe a questão da inclusão digital no dia-a-dia escolar.

Tal entrevista traz em seu corpo catorze perguntas feitas pela jornalista no que se refere desde: "jovens se relacionam com as novas tecnologias", passando por "como a escola se relaciona com esses jovens", "qual é a melhor forma de levar o tema mídia para a sala de aula" até afirmação de que "no Brasil, ainda há muita resistência ao uso da tecnologia na escola" (DIDONÊ, 2007).

Assim, Rivoltella responde às perguntas e traçando um paralelo com as escolas e ou universidades italianas e brasileiras o qual afirma que no âmbito universitário a Itália ainda não oferta cursos de graduação que forme mídia-educadores, apenas em nível de mestrado e doutorado, mas que no Brasil, em universidades como PUC/RJ e a Federal de Santa Catarina há disciplinas de Mídia e Educação nos cursos de graduação em Educação.

O entrevistado, afirma ainda que, a escola precisa se integrar à nova realidade de que seus jovens são criados numa sociedade digital e que deve tratar a assunto Mídia como tema transversal, a fim de que ocorra um trabalho em equipe na conscientização do uso e do benefício das mídias digitais em suas aulas ordinárias. Rivoltella comenta a afirmação da revista quando diz que "no Brasil, ainda há muita resistência ao uso da tecnologia na escola", ressaltando que isso não é bom, pois o Brasil fica para trás nessa questão e que na "Europa, ela já foi amplamente superada, pelo menos no que diz respeito a computadores”. Ainda que não se tenha uma formação efetiva de professores que dominem as relações de mídia e educação.

Dessa maneira, o assunto da inclusão digital é discutido sem a pretensão de analisar a temática enquanto política pública.

A autora Thais Gurgel, com colaboração de Débora Didonê e Paulo Araujo, escreveu a reportagem de capa "Inclusão é hora de aprender", trataram especificamente de analisar o desenvolvimento dos alunos portadores de deficiência nos conteúdos, demonstrando a necessidade de transcender o acolhimento e promoção de interação social dos alunos no ensino regular para uma garantia de aprendizagem.

Sendo assim, trouxe diferentes vozes como psicopedagoga, educadores, 
pesquisadores e coordenadores que corroboram a ideia defendida de que a inclusão é mais do que física, é e deve ser pedagógica no processo de ensino aprendizagem. Conforme a reportagem todos os educadores apresentados, "sabem que não basta matricular e receber na sala de aula crianças e jovens" com deficiência, pois "eles sabem que é essencial (e perfeitamente possível) ensinar" (GURGEL, p.40, 2007).

Quanto à questão da inclusão no contexto de política pública, a reportagem mencionou a importância da autonomia da escola instituindo prioridades sobre a inclusão. Entretanto, salientou que tal autonomia deva ser orientada por uma política governamental transparente. Assim, a autora sinalizou de forma positiva a iniciativa do Ministério da Educação de criar uma Política Nacional da Educação Especial na Perspectiva da Educação Inclusiva.

\section{Considerações finais}

Após analisar as reportagens que trataram da temática inclusão durante o período de 2003-2010, esta pesquisa corroborou com os principais aspectos, de forma geral publicado pela Revista Nova Escola com a temática inclusão.

Todos os textos lidos e que foram expostos pela revista Nova Escola ofereceram situações em que o resultado da inclusão pode ser positivo. Entretanto, para que isso ocorra, conforme entendimento das análises até aqui, vários requisitos são necessários e pertinentes, como: material específico, adaptação dos espaços e de infraestrutura e tarefas individuais, bem como ações parceiras para atingir os requisitos mencionados.

Mesmo evidenciar que um bom planejamento, a criatividade e a boa vontade dos professores ser fundamental para a inclusão, essa condição pode não ser suficiente para que o aluno aprenda. A inclusão implica mudar a escola como um todo, no projeto pedagógico, na postura diante dos alunos, na filosofia e oferecer serviços complementares. Destaca a importância de que as formações iniciais e continuadas estejam conectadas ao cotidiano escolar e que a educação especial deixou de ser vista como sistema paralelo ou segregado, mas passou a ser um conjunto de recursos que a escola regular deverá dispor para atender à diversidade de seus alunos.

Do ponto de vista pedagógico, segundo podemos verificar nas reportagens, é necessária à construção de um modelo que se comprometam o currículo e a avaliação e, principalmente, as atitudes em relação a essa nova postura. Enquanto que, do ponto de vista burocrático, é necessário, sempre que uma matrícula de um deficiente for solicitada, cabe ao corpo diretivo buscar orientação médicas e educacionais.

Na escola inclusiva, a identidade se constrói com a valorização das qualidades de cada um dos estudantes. Deve ser identificado e exaltado as capacidades de cada um, em vez de 
colocar em primeiro plano suas limitações. Adotar uma postura positiva e incentivar o desenvolvimento das habilidades dos estudantes para que eles possam se conhecer e perceber o que têm de bom. O preconceito começa dentro das salas de aulas. Um dos exemplos apresentados é o das meninas que precisam ser incluídas nas discussões cientificas de Ciências e Matemática, pois acabam ficando com os relatórios, e não participam diretamente das pesquisas.

A partir das experiências apresentadas sobre inclusão, a revista, reforça a necessidade de a escola repensar sua prática e seu papel social. Orientar, escutar, planejar, juntos, são ações necessárias nos casos de inclusão. Devem vir acompanhadas de um diagnóstico institucional da criança a ser incluída. Já os órgãos públicos precisam dar condições de trabalho e instrumentos aos seus profissionais, isto é, precisamos ter uma visão absolutamente ampla do indivíduo, de seu modo de vida, de sua cultura, de seu mundo real, enfim, reconhecendo, principalmente, suas potencialidades.

Os textos levam o leitor à reflexão a respeito de que estamos vivendo um momento de ajustar as necessidades dos profissionais da educação às necessidades dos alunos. Para isso, demonstram a pertinência de direcionar os esforços na atuação dos gestores, no aproveitamento dos recursos, na reorganização dos sistemas de ensino para que seja possível guiar o professor, como propulsor que é; apoiá-lo a não esperar esquemas pré-definidos; acompanhá-lo na construção dos saberes para que possa, com autonomia, efetivar na sala de aula inclusiva e tornar-se sujeito da aprendizagem e de sua atuação profissional. A educação inclusiva já é realidade no ensino regular e isso se deve aos esforços de alguns educadores e gestores que perceberam a necessidade de mudar.

Fica nítido que a inclusão não é simples. É um processo cheio de imprevistos, não tem fórmula pronta e requer constante aperfeiçoamento de todos os envolvidos no processo da aquisição do conhecimento pelo educando.

A inclusão só não acontece se houver discriminação. Discriminação surge da necessidade que temos de qualificar as coisas e os indivíduos dentro do que é socialmente considerado normal.

A inclusão digital nas escolas públicas também é abordada pela Revista, que revela em suas perguntas e na escolha do entrevistado sua postura favorável à inclusão da tecnologia nas salas de aulas ordinárias, bem como defende que os jovens de hoje já estão direta ou indiretamente inseridos numa sociedade digital. Por outro lado, não problematiza de fato a carência de suportes como: ferramentas tecnológicas, investimento em formação contínua de professores e professoras e de ações que tangem as políticas públicas (efetivas) que possam garantir o acesso às mídias digitais destes jovens de diferentes esferas sociais no Brasil.

Dentre os sete textos analisados, sendo seis reportagens e uma entrevista, observamos 
que o tema da inclusão foi debatido e defendido como ação positiva, desde a inclusão de pessoas com deficiência, passando pela inclusão de gênero à inclusão digital.

O corpo como processo atribui ao mesmo uma conotação de mutabilidade, ou seja, a significação de sua construção se mostra de modo permeável às marcas da/na cultura. A produção imaginária sobre esse corpo apresentará as normas culturais inscritas e reforçadas pela produção de conhecimento. As qualidades que envolve as ações relativas à docência se apresentam condicionadas às influências presentes no/do corpo. As necessidades, os anseios, os desejos, devem assumir relevância em ações e planejamentos que se relacionam a esse setor. Permitir transformações, entendimentos e releituras significa estabelecer um encontro com a produção imaginária em torno do conhecer.

Contudo, no contexto de analisar a temática inclusão diante à postura das reportagens publicadas na Revista Nova Escola durante o período de 2003-2010, constatou-se que apenas uma reportagem tratou da questão inclusão enquanto política pública, no entanto, se posicionando de forma positiva e sem crítica dessa questão, limitando-se aos aspectos de âmbito escolar.

\section{Referências}

BACHELARD, Gaston. A poética do devaneio. São Paulo: Martins Fontes, 1988.

BACZKO. Bronislaw. Imaginação social. Enciclopédia Einaudi, s. 1. Lisboa: Imprensa Nacional/Casa da Moeda, Editora Portuguesa, 1985.

BETTI, M. Educação Física e Sociologia: novas e velhas questões no contexto brasileiro. In: CARVAlHO, M. C.; RUBIO, K. Educação Física e Ciências Humanas. Hucitec: São Paulo, 2001.

CASTORIADIS, C. A instituição imaginária da sociedade. $3^{\text {a }}$ edição. Rio de Janeiro: Paz e Terra, 1982.

CAVALCANTE, Meire. Aparências diferentes? Talentos também. Revista Nova Escola. São Paulo, n. 173, Junho/Julho, 2004, p.32-33.

. A sociedade em busca de mais tolerância. Revista Nova Escola. São Paulo, n. 196, Outubro, 2006, 34-36.

CERTEAU, M. A invenção do cotidiano. Petrópolis: Vozes, 1982.

DAOLIO, J. Educação Física e o conceito de cultura. Campinas: Autores Associados, 2004.

DIDONÊ, Débora. Falta cultura digital na sala de aula. Revista Nova Escola. São Paulo, n. 200, Março, 2007, p.15-18.

ELIAS, Norbert. A sociedade dos indivíduos. Rio de Janeiro. Jorge Zahar, 1994a.

FERREIRA, N. T.; EIZIRIK, M. F. Imaginário social e educação: revendo a escola. Em ISSN 2526-2882 
Aberto, n.61, Brasília, 1994.

GEERTZ, Clifford. A interpretação das culturas, Rio de Janeiro : LTC Editora, 1989.

GOELLNER, Silvana Vilodre. A produção cultural do corpo. In: LOURO, Guacira Lopes; FELIPE, Jane; GOELLNER, Silvana Vilodre (Orgs.). Corpo, gênero e sexualidade: um debate contemporâneo na educação. 3. ed. Petrópolis, RJ: Vozes, 2007.

GUIMARÃES, Arthur. Inclusão que funciona. Revista Nova Escola. São Paulo, n. 165, Setembro, 2003, p.43-47.

GURGEL, Thais. Inclusão, só com aprendizagem. Revista Nova Escola. São Paulo, n. 206, Outubro, 2007, p.38-45.

IMBERNÓN, F. Formação permanente do professorado: novas tendências. São Paulo: Cortez, 2009.

MARTINS, P. H. A sociologia de Marcel Mauss: Dádiva, simbolismo e associação. Revista Crítica de Ciências Sociais, 73, 2005: 45-66.

MAUSS, Marcel. As técnicas do Corpo. In AA.VV., Corpo, Colecção Arte e Sociedade (Dir. João Valente Aguiar), n. ${ }^{0}$ 1, Lisboa: Apenas Livros | Instituto de Sociologia da Faculdade de Letras da Universidade do Porto, 2009.

MORIN, Edgar. Os sete saberes ligados à educação do futuro. São Paulo: Cortez; Brasília: Unesco, 2000.

MORO, Cláudia C. Sala de aula sem preconceito. Revista Nova Escola. São Paulo, n. 172, Abril, 2004, p.21.

PELLEGRINI, Denise. Juntos, todos aprendem mais. Revista Nova Escola. São Paulo, n. 201, Abril, 2007, p.46-49.

ROSSI, F. Formação continuada em Educação Física escolar: concepções e perspectivas de professores. 2010. 211f. Dissertação (Mestrado em Ciências da Motricidade) - Instituto de Biociências da Universidade Estadual Paulista, Rio Claro, 2010.

ROSSI, F. Implicações da formação continuada na prática pedagógica do(a) professor(a) no âmbito da cultura corporal do movimento. 2013. Tese (Doutorado em Ciências da Motricidade) - Instituto de Biociências daUniversidade Estadual Paulista, Rio Claro, 2013.

SANTIN, S. Reflexões antropológicas sobre a educação física e o esporte escolar. In:

Educação física: uma abordagem filosófica da corporeidade. Ijuí: Editora Unijuí, 1987.

SILVA, Ana Márcia. Das práticas corporais ou porque Narciso se exercita. In: Revista Brasileira de Ciências do Esporte. Vol.17, n.3, maio, 1996, p. 244-251. 


\section{Biografia Resumida}

Carlos da Fonseca Brandão (Unesp/Assis): Licenciado em Educação Física e Pedagogia, Mestre em Educação: História, Política, Sociedade pela PUC - SP (1994), Doutor em Educação pela UNESP - Marília (2000), Livre-docente em Estrutura e Funcionamento do Ensino Fundamental e Médio pela UNESP Assis (2006) e Pós-doutor pela Universidad Autónoma de Barcelona - UAB (2011), pela Universitat Rovira I Virgili (2015) e pela Uppsala Universitet (Suécia - 2017). Atualmente é professor adjunto do Departamento de Educação da UNESP - Assis e do Programa de Pós-graduação em Educação da UNESP - Marília. Foi Professor Visitante na Universidade do Porto (Portugal 2009), na Universidad de Granada (Espanha - 2009), na Universidad Nacional de Córdoba (Argentina - 2010), na Universidad de Santiago de Compostela (Espanha - 2011), na Universidad de Santiago do Chile (Chile - 2012), na Universidad Nacional de Cuyo (Mendoza, Argentina - 2013) e na Universidad Nacional del Sur (Bahía Blanca, Argentina - 2018). Tem experiência na área de Educação, atuando na docência e na pesquisa em política educacional, educação, controle das emoções e processos de civilização. Possui livros publicados pelas editoras Avercamp, Autores Associados, Edusc, Poiesis, UNESP e Vozes, entre outras.

Contato: cbrandao@assis.unesp.br

Link para Lattes: http://lattes.cnpq.br/1796435646239496

Chelsea Maria de Campos Martins: Graduação em Licenciatura plena em Pedagogia (1991) e Ciências Físicas e Biológicas (1989) pela Faculdade de Educação São Luís. Especialização em Gestão da rede pública para Supervisores -USP/FEAC. Mestre em Educação Escolar pela Universidade Estadual Paulista Júlio de Mesquita- Unesp/ Araraquara (2001). Doutoranda em Educação Escolar na Unesp/ Marília (2019) Atualmente é professora de ensino superior e coordenadora do Nucleo de Apoio à Atividades Academicas (NAAc) no Centro Universitário Moura Lacerda - 
Unidade III/ Jaboticabal/SP e Supervisora de Ensino da Diretoria de Ensino -Região de Taquaritinga/ Secretaria de Educação do Estado de São Paulo (SEE/SP). Avaliadora Basis/Sinais/INEP, nos cursos de Pedagogia. Experiência no Ensino Superior e Educação Básica atuando principalmente, nos seguintes temas: gestão educacional, políticas públicas, Educação Física, supervisão de ensino, Formação de Professores e Diretores de Escola.

Link para Lattes: http://lattes.cnpq.br/9427674665976275

Contato: chelseamcmartins@yahoo.com.br

Samuel Gonçalves Pinto: Graduado em Educação Física (UFV) e Pedagogia (UNIUBE), atua como Gestor de Projetos Sociais, Coordenador de Curso e Professor no Ensino Superior, realizando ações em diferentes associações, segmentos e instituições. Especialista em Gestão de Políticas Públicas (UFV) e Lazer (UFMG). Pós Graduando em Esportes e Atividades Físicas para Pessoas com Deficiência (UFJF) e em Ativação de Processos de Mudanças na Formação Superior de Profissionais de Saúde (FIOCRUZ). Atua no ensino desde 2006, quando assumiu como Professor do Ensino Superior, com experiência na graduação nos cursos de Direito, Educação Física, Fisioterapia, Pedagogia e Ciências Contábeis. Desde o ano de 2008, atua com Coordenador de Curso, na área de Educação Física. Avaliador Basis/Sinais/INEP, nos cursos de Pedagogia e Educação Física. Experiência em Ensino, Pesquisa e Extensão, nos seguintes temas: Formação Docente, Educação Inclusiva, Avaliação, Políticas Públicas, Educação em Direitos Humanos, Justiça Restaurativa, Sociedade e Cultura, Corporeidade e Comunicação Não Violenta. Mestre em Economia Doméstica (UFV) e Doutor em Ciências do Exercício e do Esporte (UERJ), Pós Doutor em Educação Física (UNESP/BAURU), atua também como Professor em Cursos de Pós Graduação e Presidente da Comissão Própria de Avaliação-CPA-FUPAC/Ponte Nova.

Link para Lattes: http://lattes.cnpq.br/2049611731367329

Contato: samuel.pto@gmail.com 